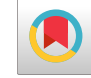

\title{
Associated Etiologies of Enuresis in 5-to-15-Year-Old-Children
}

\author{
Simin Sadeghi-Bojd (D) ${ }^{1}$, Mahboube Firouzkouhi Moghaddam $\left(^{2}{ }^{2}\right.$, Elham Sharafkhani ${ }^{3}$, Seyed Hosein \\ Soleimanzadeh Mousavi (iD ${ }^{4}$ and Saeedeh Yaghoubi (iD) ${ }^{5,}$ \\ ${ }^{1}$ Children \& Adolescent Health Research Center, Resistant Tuberculosis Institute, Zahedan University of Medical Sciences, Zahedan, Iran \\ ${ }^{2}$ Department of Psychiatry, School of Medicine, Baharan Psychiatric Hospital, Zahedan University of Medical Sciences, Zahedan, Iran \\ ${ }^{3}$ Department of Obstetrics and Gynecology, School of Medicine, North Khorasan University of Medical Sciences, Bojnurd, Iran \\ ${ }^{4}$ Department of Pediatrics, School of Medicine, Ali-Ibn-Abitaleb Hospital, Zahedan University of Medical Sciences, Zahedan, Iran \\ ${ }^{5}$ Department of Pediatrics, School of Medicine, Children and Adolescents Health Research Center, Research Institute for Drug Resistant Tuberculosis, Ali-Ibn-Abitaleb \\ Hospital, Zahedan University of Medical Sciences, Zahedan, Iran \\ "Corresponding author: Department of Pediatrics, School of Medicine, Children and Adolescents Health Research Center, Research Institute for Drug Resistant Tuberculosis, \\ Ali-Ibn-Abitaleb Hospital, Zahedan University of Medical Sciences, Zahedan, Iran. Email: yaghoubimd@yahoo.com
}

Received 2020 December 08; Revised 2021 February 07; Accepted 2021 April 14.

\section{Abstract}

Background: Enuresis is one of the most common problems in children with physical and psychological complications that can disturb their social relationships. The main objective of this study is to evaluate the relationship between enuresis and its associated etiologies in children aged 5 to 15 years in Zahedan. The study further contributes to an early realization of the parents of children with enuresis-associated problems.

Methods: Following a descriptive design, 200 children (5 to 15 years old) suffering from enuresis referred to nephrology and psychiatric clinics in Zahedan in 2019 were recruited. Data were analyzed using SPSS software.

Results: Of 200 children with enuresis, 134 (67\%) were girls, and 66 (33\%) were boys. Also, 174 (87\%) were aged 5 - 10 years, and only 26 (13\%) were 10 to 15 years old. Birth weight of 172 (86\%) children was $2500-4000$ g, $20(10 \%)$ were $<2500$ g, and only $8(4 \%)$ were $>4000$ g. Fecal incontinence was observed in 99 cases (49\%), and 101 (51\%) did not have fecal incontinence. Attention deficit hyperactivity disorder (ADHD) was found in 80 (40\%) cases. For 144 (72\%) children, we found no stress, and 56 children (28\%) had stress. Urinary tract infection was observed in 142 children (71\%). According to imaging studies, 34 children (17\%) with enuresis had congenital kidney abnormalities and 166 (83\%) had no kidney problems.

Conclusions: The significant etiologies typically found in the onset of enuresis and its exacerbation can be controlled or treated. Since the complications of enuresis have not been properly clarified for families, it is of crucial importance to increase awareness about this health problem.

Keywords: Enuresis, Children, Related Factors

\section{Background}

Nocturnal enuresis is involuntary urination that happens at night while sleeping, after the age when a person should be able to control his/her bladder $(1,2)$. According to the definition developed by International Children's Continence Society (ICCS), it is concerned that nocturnal enuresis remains underdiagnosed in children until the age of seven or eight years (1). It affects approximately $15 \%$ of all children at the age of 5-years and is more common among boys $(3,4)$. Firoozkoohi et al. investigated the prevalence of enuresis in school-age children in Zahedan and reported a prevalence of $7 \%$ for NE in boys and 3\% in girls (5).

Enuresis is classified according to the presence of lower urinary tract symptoms (LUTS) as monosymptomatic and non-monosymptomatic. In addition, it can be divided based on the dryness prolongation into primary ( $<6$ months' dryness) and secondary (relapse after $>6$ months of dryness) (6). According to this definition, $80-90 \%$ of cases are diagnosed as primary enuresis. According to previous studies, NE is a multifactorial disease characterized by a complex interaction of genetic, developmental and psychosocial factors $(6,7)$. Some well-known etiologies include electrolyte imbalance, decreased antidiuretic hormone (ADH) levels, and decreased bladder capacity.

Furthermore, disease-like symptoms, including constipation, encopresis, urinary tract infection (UTI), suprapubic pain, asymptomatic bacteriuria, vesicoureteral reflux, neuropsychiatric disorders, learning disabilities, and sleep disorders, are both relevant and important for nocturnal enuresis $(8,9)$. In addition, a predictive association has been postulated between factors like ethnicity, 
age, gender, birth order, education level and employment status of parents, family size, income, socio-economic status, bedtime habits, arousal dysfunction with NE (10). Nocturnal enuresis can lead to a constant feeling of distress, which eventually results in chronic stress. In addition, it has negative impacts on the emotional well-being of children, which in turn affects their self-esteem and social development. Children suffering from NE have lower levels of self-esteem, mental health, skills, and poor relation with their parents and others. Considerably, following receiving treatment for nocturnal enuresis, children who become completely dry have higher self-esteem than those with persisting nocturnal enuresis $(11,12)$.

Children diagnosed with NE are at increased risk of psychiatric disorders by 2 - 6 times because of embarrassment, low self-esteem, aggression, and perform poorly in life and society (1).

\section{Objectives}

The current study aimed to investigate the association between enuresis and some associated etiologies to both inform parents and to prevent the occurrence of enuresis problems.

\section{Methods}

Following a prospective design, the current study was performed by specialists from various disciplines like pediatric, nephrology, and child psychiatry (of Zahedan University of Medical Sciences) in 2019. To diagnose patients with MNE (Monosymptomatic Nocturnal Enuresis) a structured protocol was applied. Also, the inclusion criteria being aged between 5 to 15 years and MNE (Monosymptomatic Nocturnal Enuresis) diagnosis according to the ICCS criteria (International Children's Continence Society) $(13,14)$.

Informed consent was obtained from the patient's parents. Then, all participants were examined by a pediatric nephrologist, and a child psychiatrist and necessary data were collected using researcher-developed checklists. The checklist was comprised of two sections. The first section contained data on variables of age, gender, birth weight, constipation history, fecal incontinence, urinary tract infection, kidney abnormalities, urine analysis, ultrasound, and other imaging procedures were collected. The second section was comprised of Psychological stressors and ADHD.

In terms of birth weight, participating children were classified into 3 groups of less than 2500 grams, 4000 2500 grams, and more than 4000 grams. The data regarding the birth weight were obtained through the history given by parents or children's growth cards. Fecal incontinence was investigated according to DSM-IV criteria for defecation at least once a month for 3 consecutive months, voluntary or involuntary, with or without constipation in a place other than the toilet (3). A history of constipation for less than 3 times a week or more than $25 \%$ of total bowel movements was considered painful.

Ultrasound and other imaging techniques were used to assess congenital kidney abnormalities. An ultrasound specialist examined the genitourinary system, which included the morphology and capacity of the bladder, postvoid residual (normal $20 \mathrm{~mL}$ ), and bladder thickness ( $3 \mathrm{~mm}$ was considered normal). The measured bladder volume was considered as decreased if it was less than $65 \%$ of the expected volume and as elevated if it was more than $150 \%$ of the expected volume for a given age $(15,16)$. Ultrasound was used to diagnose constipation. Rectal transverse diameter (normal $30 \mathrm{~mm}$ ) was considered as a diagnostic factor $(2,17)$. Finally, ICCS criteria were used to diagnose NE, and its multiple periods were defined as more than 4 times (2).

The urine culture of more than 100,000 microorganisms in the midstream urine sample was considered as urinary tract infection. In the second questionnaire, which was completed by a pediatric psychiatrist, any psychological or frightening stress event that probably has negatively affected the child during the last 6 months was considered as psychological stressor. The presence of ADHD, based on the symptoms along with dysfunctional behavior of the child for at least 6 months, was studied according to DSM-IV criteria (4).

This study was approved by the Ethical Committee of the Zahedan University of Medical Sciences (thesis code: 1333). Finally, data analysis was administered using SPSS version 20.

\section{Results}

A total of 200 children aged 5 to 15 years suffering from enuresis referred to nephrology and pediatric psychiatric clinics in Zahedan were studied in the present study. Of 200 children with enuresis, 134 (67\%) were girls and 66 (33\%) were boys. Also, 174 children (87\%) were 5 - 10 years old, and only 26 (13\%) were 10 to 15 years old. Among them, 172 children (86\%) weighed 2500 - $4000 \mathrm{~g}$ at birth, 20 (10\%) weighed less than 2500 g, and only 8 (4\%) weighed more than 4000g. Fecal incontinence was observed in 99 children (49\%), and 101 children (51\%) did not have fecal incontinence. Constipation was absent in 116 patients (58\%) and 84 patients (42\%) had constipation. According to the DSMIV criteria, 80 children (40\%) were ADHD, and 120 (60\%) did not fulfill the criteria. Psychological stressors such as the death of family members, moving house or school, and parental quarrels were absent in 144 children (72\%), and 56 (28\%) had these stressors. Furthermore, 142 children (71\%) 
did not have UTI, and only 58 children (29\%) had UTI. According to imaging studies, 34 children (17\%) with enuresis had congenital kidney abnormalities, and 166 (83\%) had no kidney problem. All data are provided in Table 1.

\begin{tabular}{|c|c|}
\hline Risk Factors & Have Enuresis, No. (\%) \\
\hline \multicolumn{2}{|l|}{ Birth weight (g) } \\
\hline Less than 2500 & $20(10)$ \\
\hline $2500-4000$ & $172(86)$ \\
\hline More than 4000 & $8(4)$ \\
\hline \multicolumn{2}{|l|}{ Fecal incontinency } \\
\hline Yes & $99(49)$ \\
\hline No & $101(51)$ \\
\hline \multicolumn{2}{|l|}{ Constipation } \\
\hline Yes & $84(42)$ \\
\hline No & $116(58)$ \\
\hline \multicolumn{2}{|l|}{ ADHD } \\
\hline Yes & $80(40)$ \\
\hline No & $120(60)$ \\
\hline \multicolumn{2}{|l|}{ Psychologic stressor } \\
\hline Have & $56(28)$ \\
\hline Not have & $144(72)$ \\
\hline \multicolumn{2}{|l|}{ Urinary tract infection } \\
\hline Yes & $58(29)$ \\
\hline No & $142(71)$ \\
\hline \multicolumn{2}{|c|}{ Congenital kidney abnormalities } \\
\hline Yes & $34(17)$ \\
\hline No & $166(83)$ \\
\hline
\end{tabular}

\section{Discussion}

Enuresis is one of the most common problems in children with physical and psychological complications that can disturb their social relationships. This study was performed on 200 children aged 5 - 15 years with enuresis referred to nephrology and psychiatric clinics in Zahedan in 2017. The number of girls suffering from enuresis was two times greater than boys, mostly among those aged 5 to 10 years. The prevalence of enuresis is negatively associated with age. Children with enuresis mostly weighed 2500 to $4000 \mathrm{~g}$ at the time of birth or slightly less than $2500 \mathrm{~g}$ or slightly more than $4000 \mathrm{~g}$. Half of the children with nocturnal enuresis had fecal incontinence, and there seems to be a close association between the causes of urinary incontinence and fecal incontinence. We also found a significant association between constipation, ADHD, and enuresis. In this study, approximately half of children with enuresis had constipation and ADHD, and less than one-third of the participants had psychological stressors, congenital kidney disorders, and UTI.
Gunes et al. (2009) concluded that UTI and younger age were effective factors in the development of enuresis. Psychological stressors are not associated with nocturnal enuresis. There is also no significant gender difference between patients (18). According to the findings, enuresis is more prevalent among girls. The observed difference can be attributed to cultural differences. Most parents mentioned the presence of enuresis in girls as a serious problem, but in boys, this issue is not that much important. Most of those referred to our clinic are girls. These factors may have contributed to the increased prevalence of enuresis in girls in our study. Furthermore, the lower prevalence of UTIs in the present study, compared to previous studies, can be attributed to the sensitivity and accuracy of applied laboratory evaluation.

In their study, Sureshkumar et al. (2005) found that the male gender was highly associated with severe enuresis, while constipation and psychological stress were related to moderate enuresis. The prevalence of constipation in children with enuresis is $7.5 \%$. Constipation and fecal incontinence were effective factors and were more prevalent in our study (19). Shreeram et al. (2004) identified ADHD as one of the strongest risk factors for enuresis development, which is similar to the results of the present study (20). Akhavan Karbasi (2006 - 2005) concluded that the prevalence of enuresis is higher in boys (contrary to the present study), and there is no association between family history, birth rank, and enuresis. In the present study, we did not consider these two factors (21). EmamGhoraishy concluded that a history of UTI has no effect on the prevalence of enuresis. There is no association between parents' education level, number of children, economic status, and enuresis, which was not investigated in the present study (22). Dehghani et al. (2006) reported a significant association between the history of UTI and mental stressors with enuresis. In our study, psychological stress was not significantly associated with enuresis (23). Osungbade (2003) reported that for $33 \%$ of all cases, enuresis was caused by a UTI, which is slightly higher than the value found in the present study (29\%) (24). Fatahi Bayat (2001) concluded that enuresis is more common in girls and there is a significant association between UTI and enuresis, which we did not investigate (17).

Percentage difference in enuresis-related factors is one of the differences observed in this study as compared to other studies, which can be attributed to racial and cultural differences. In these cases, psychological stress reported by parents is unreliable because parents pay less attention to constipation than enuresis in their children.

\subsection{Conclusion}

In the present study, 200 children with enuresis were investigated. According to the findings, enuresis is more 
prevalent in females, in children aged 5-10 years, and those with a birth weight of $2500-4000$ g. Constipation and ADHD were found to be significantly associated with the occurrence of enuresis, which indicates the need for further evaluation. Enuresis was not evident in cases of UTIs, mental stress, and congenital kidney disorders.

\section{Acknowledgments}

The authors pay their regard and are thankful to the Emergency Medical Service Personnel, Pediatric Residents, Nurses, and Emergency Physicians, and all those who participated in the present study. This article was supported by the Children and Adolescents Health Research Centre of Zahedan.

\section{Footnotes}

Authors' Contribution: All authors collaborated in all stages of the design, data collection, and writing of the article. Dr. Yaghoubi, as the responsible author, submitted the article.

Conflict of Interests: The authors report no conflicts of interest. The authors alone are responsible for the content and writing of this article.

Ethical Approval: This study was approved by the Ethical Committee of Zahedan University of Medical Sciences.

Funding/Support: This study was supported by nowhere. Informed Consent: Informed consent was obtained from the patient's parents.

\section{References}

1. Austin PF, Bauer SB, Bower W, Chase J, Franco I, Hoebeke P, et al. The standardization of terminology of lower urinary tract function in children and adolescents: Update report from the standardization committee of the International Children's Continence Society. Neurourol Urodyn. 2016;35(4):471-81. doi: 10.1002/nau.22751. [PubMed: 25772695].

2. Jalkut MW, Lerman SE, Churchill BM. Enuresis. Pediatr Clin North Am. 2001;48(6):1461-88. doi: 10.1016/s0031-3955(05)70386-2. [PubMed: 11732125].

3. von Gontard A, Mauer-Mucke K, Pluck J, Berner W, Lehmkuhl G. Clinical behavioral problems in day- and night-wetting children. Pediatr Nephrol. 1999;13(8):662-7. doi: 10.1007/s004670050677. [PubMed: 10502123].

4. Feldman MD, Christensen JF. Behavioral medicine: A guide for clinical practice. New York, USA: McGraw-Hill Medical; 2008. Available from: http://accessmedicine.mhmedical.com/book.aspx?bookId=373.

5. Firouzkouhi Moghaddam M, Sadeghi Bojd S, Pishjoo M, Ghafari A. The Prevalence of enuresis in school age children in Zahedan in 2013-2014. Int J Med Invest. 2015;4(3):313-7.

6. Nappo S, Del Gado R, Chiozza ML, Biraghi M, Ferrara P, Caione P. Nocturnal enuresis in the adolescent: A neglected problem. BJU Int 2002;90(9):912-7. doi: 10.1046/j.1464-410x.2002.03030.x. [PubMed: 12460356].
7. Bayoumi RA, Eapen V, Al-Yahyaee S, Al Barwani HS, Hill RS, Al Gazali L. The genetic basis of inherited primary nocturnal enuresis: A UAE study. J Psychosom Res. 2006;61(3):317-20. doi: 10.1016/j.jpsychores.2006.05.010. [PubMed:16938508].

8. Austin PF, Bauer SB, Bower W, Chase J, Franco I, Hoebeke P, et al. The standardization of terminology of lower urinary tract function in children and adolescents: Update report from the standardization committee of the International Children's Continence Society. Neurourol Urodynam. 2016;35(4):471-81. doi: 10.1002/nau.22751.

9. Sadeghi-Bojd S, Hashemi M. Hypercalciuria and recurrent urinary tract infections among children in Zahedan, Iran. J Pak Med Assoc. 2008;58(11):624-6. [PubMed: 19024135].

10. Wang QW, Wen JG, Song DK, Su J, Zhu QH, Liu K, et al. Bed-wetting in Chinese children: Epidemiology and predictive factors. Neurourol Urodyn. 2007;26(4):512-7. doi: 10.1002/nau.20373. [PubMed: 17315220].

11. Warzak WJ. Psychosocial implications of nocturnal enuresis. Clin Pe diatr (Phila). 1993;Spec No:38-40. doi: 10.1177/0009922893032001s09. [PubMed: 8039339].

12. National Clinical Guideline Centre (UK). Nocturnal enuresis: The management of bedwetting in children and young people. Nocturna Enuresis: The Management of Bedwetting in Children and Young People. London, UK: Royal College of Physicians; 2010.

13. Neveus T, von Gontard A, Hoebeke P, Hjalmas K, Bauer S, Bower $\mathrm{W}$, et al. The standardization of terminology of lower urinary tract function in children and adolescents: Report from the Standardisation Committee of the International Children's Continence Society. J Urol. 2006;176(1):314-24. doi: 10.1016/S0022-5347(06)00305-3. [PubMed: 16753432].

14. Yousef KA, Basaleem HO, bin Yahiya MT. Epidemiology of nocturnal enuresis in basic schoolchildren in Aden Governorate, Yemen. Saudi Kidney Dis Transpl. 2011;22(1):167-73. [PubMed: 21196640].

15. Jequier S, Rousseau O. Sonographic measurements of the normal bladder wall in children. AJR Am J Roentgenol. 1987;149(3):563-6. doi: 10.2214/ajr.149.3.563. [PubMed: 3303881].

16. Joensson IM, Siggaard C, Rittig S, Hagstroem S, Djurhuus IC Transabdominal ultrasound of rectum as a diagnostic tool in childhood constipation. J Urol. 2008;179(5):1997-2002. doi: 10.1016/j.juro.2008.01.055. [PubMed: 18355856].

17. Fatahi Bayat GA, Marefati S. [A comparative study between desmopressim and imipramine in the management of nocturnal enuresis] Journal of Arak University of Medical Sciences. 2001;4(2):7-12. Persian.

18. Gunes A, Gunes G, Acik Y, Akilli A. The epidemiology and factors associated with nocturnal enuresis among boarding and daytime school children in southeast of Turkey: A cross sectional study. BMC Public Health. 2009;9:357. doi: 10.1186/1471-2458-9-357. [PubMed: 19772657]. [PubMed Central: PMC2754466].

19. Sureshkumar P, Jones M, Caldwell PH, Craig JC. Risk factors for nocturnal enuresis in school-age children.JUrol.2009;182(6):2893-9. doi 10.1016/j.juro.2009.08.060. [PubMed:19846154].

20. Shreeram S, He JP, Kalaydjian A, Brothers S, Merikangas KR Prevalence of enuresis and its association with attentiondeficit/hyperactivity disorder among U.S. children: Results from a nationally representative study. J Am Acad Child Adolesc Psychiatry. 2009;48(1):35-41. doi: 10.1097/CHI.0b013e318190045c. [PubMed: 19096296]. [PubMed Central: PMC2794242].

21. Akhavan Karbasi S, Golestan M, Fallah R. [Enuresis in 6 year old children and its related factors]. The Horizon of Medical Sciences. 2009;15(3):63-9. Persian.

22. EmamGhoraishy F. [Evaluation of prevalence of enuresis in school age children in Jahrom and related factors]. Pars of Jahrom University of Medical Sciences. 2004;1(1):6-9. Persian. doi: 10.29252/jmj.1.1.2.

23. Dehghani K, Pourmovahed Z, Dehghani H, Shakiba M, Tavangar H, Yasini Ardakani SM, et al. [The survey of enuresis related factors in school children aged 6-12 years]. Daneshvar Medicine: Basic and Clinical Research Journal. 2009;15(6):33-8. Persian.

24. Osungbade KO, Oshiname FO. Prevalence and perception of nocturnal enuresis in children of a rural community in southwestern Nigeria. Trop Doct. 2003;33(4):234-6. doi: 10.1177/004947550303300416. [PubMed: 14620431]. 